\title{
Alfabetização e letramento: qual o entendimento de professoras da educação infantil sobre estes processos?
}

\begin{abstract}
Resumo: Este artigo traz análises produzidas a partir de uma pesquisa que teve como temática central a alfabetização e o letramento, tomando como ponto de partida as falas de professoras da pequena infância. $O$ objetivo consistiu em analisar 0 entendimento de professoras que atuam na Educação Infantil sobre os conceitos de alfabetização e letramento e sobre as formas como estes processos se materializam no cotidiano das práticas pedagógicas junto às crianças pequenas. Para a geração de dados utilizou-se de um questionário com perguntas abertas, aplicado com 4 professoras que trabalham em uma instituição privada de Educação Infantil da cidade de Blumenau-SC. Para subsidiar o estudo recorreu-se à legislação - Lei de Diretrizes e Bases da Educação Nacional (9394/1996), Constituição Federal(1988), Estatuto da Criança e do Adolescente (8069/1990) e Diretrizes Curriculares Nacionais para a Educação Infantil. (CNE 5/2009) -, possibilitando traçar algumas reflexões sobre o percurso histórico de constituição dos direitos da criança. Autores como Soares(2012) e Brito(2005),foram utilizados para o aprofundamento sobre as discussões relacionadas aos processos de alfabetização e letramento, entrelaçando este diálogo no âmbito da Educação Infantil. Pela pesquisa identificou-se o quanto os processos de alfabetização e letramento podem e são trabalhados na Educação Infantil, ora como direito das crianças de acesso a linguagem escrita, ora como preparação para o ingresso nos anos iniciais do Ensino Fundamental.
\end{abstract}

Palavras-chave: Educação Infantil; Alfabetização e Letramento; Direitos da Criança.

\begin{abstract}
This article presents analysis produced from a survey that had as its central theme on initial reading instruction and literacy, taking as its starting point the early childhood teachers speeches. The aim was to analyze the understanding of teachers who work in early childhood education on initial reading instruction and literacy concepts and the ways how these processes materialize in daily teaching practices among small children. For the generation of data we used a questionnaire with open questions, applied to 4 teachers working in a private institution of Early Childhood Education of the city of Blumenau-SC. To support the study turned to the law - LDB (9394/1996), CF (1988), ECA (8069/1990) and the National Curriculum Guidelines for Early Childhood Education. (CNE 5/2009) providing find out some reflections on the historical background of children's rights constitution. Authors like Soares (2012) and Brito (2005) were used for the strengthening of the discussions related to initial reading instruction and literacy processes, linking this dialogue within the scope of Early Childhood Education. By this research, may be identified how the initial reading instruction and literacy
\end{abstract}

\footnotetext{
'Professora de Educação Infantil. Formada em Pedagogia e com especialização em Alfabetização e Letramento, pela Universidade Regional de Blumenau - FURB. E-mail: jeh_trainotti@yahoo.com.br

${ }^{2}$ Doutora em Educação Pela Universidade Federal de Santa Catarina PPGE/UFSC. Professora e coordenadora do curso de Pedagogia do IFC - campos Blumenau. E-mail: roseli.nazario@blumenau.ifc.edu.br
} 
processes can and are worked in Early Childhood Education, as the children's right to access to written language, or as preparation for entrance in the early years of elementary school.

Keywords: Early Childhood Education; initial reading instruction and literacy; Child's Rights.

\section{Breve introdução para localizar o leitor}

pesquisa em questão apresenta uma reflexão sobre alfabetização e letramento no âmbito
da Educação Infantil, a partir de um estudo que teve como objetivo analisar o
entendimento de professoras que atuam neste nível educativo sobre os conceitos de alfabetização e letramento e sobre as formas como estes processos se dão no cotidiano das suas práticas junto de crianças pequenas ${ }^{3}$.

A pesquisa de campo aconteceu em uma instituição vinculada à rede privada de ensino do município de Blumenau/SC, que atende crianças de faixas etárias compreendidas entre 2 e 5 anos. A metodologia empregada consistiu na aplicação de questionário com perguntas abertas com 4 professoras que atuam em diferentes turmas de Educação Infantil, assim organizadas: nível A, correspondente ao trabalho realizado com crianças de 2 anos de idade; nível B, crianças de 3 anos; nível C, crianças de 4 anos; nível D, crianças de 5 anos.

A escolha destas 4 professoras se deu a partir dos seguintes critérios: tempo de serviço na Educação Infantil, atuação nas faixas etárias acima mencionadas e, por fim, o manifesto desejo por participar deste estudo. Desta seleção resultou, então, as profissionais mais antigas da instituição, todas com formação em Pedagogia e pós-graduação na área da educação. Em se tratando da instituição que se constituiu em campo de pesquisa, esta seleção é justificada por se tratar do espaço de atuação profissional de uma das autoras deste artigo.

Anterior ao início das discussões relativas ao estudo, resta mencionar que o tema para o presente artigo foi provocado pelas inquietações que marcam a trajetória profissional de uma das autoras, a qual, no cotidiano de atuação na Educação Infantil, se depara com diferentes compreensões e práticas pedagógicas diversas que, por vezes, se mostram antagônicas sobre os processos de alfabetização e letramento, em especial, quando relacionados à educação de crianças pequenas.

${ }^{3}$ Ao nos referirmos as crianças pequenas neste artigo estamos fazendo menção aquelas com idades compreendidas entre 0 e 6 anos, que frequentam os contextos de Educação Infantil, em concordância com as discussões da área. 


\section{A criança de direitos e o direito da criança à educação infantil}

No que diz respeito ao entendimento sobre a infância como um tempo de direitos, podemos inferir que esta é uma discussão bastante recente no cenário brasileiro, considerando que amplia-se legalmente este preceito com a promulgação da Constituição Federal de 1988, quando se faz uma análise mais aprofundada das constituições anteriores.

Embora a discussão em torno dos direitos da criança não se constitua em objeto direto de análise para este estudo, optamos por fazer uma breve incursão na história legal brasileira, no que se refere às Constituições Federais, de modo a dar visibilidade ao lugar destinado (ou não) às crianças e à infância na letra da lei, a partir do século XX.

A Constituição Federal de 1934 faz menção a categoria infância em 3 artigos, quando trata do amparo à maternidade e à infância como direito social do trabalhador (art.121); como incumbência do Poder Pública (art. 138); na manutenção de renda tributária específica para amparo à maternidade e à infância (art.141).

No tocante da Constituição Federal de 1937, amplia-se um artigo em relação à Carta anterior. Ao tratar das competências do Estado, no artigo 15 - IX, promulga-se o dever de fixação de bases e determinação dos quadros da educação nacional, traçando as "diretrizes que devem obedecer a formação física, intelectual e moral da infância e da juventude". Pelo artigo 122 assegurase o direito à liberdade, à segurança individual e à propriedade aos cidadãos brasileiros e estrangeiros que morem no país, bem como o direito de manifestação de pensamento, prevendo que a lei pode prescrever: "b) medidas para impedir as manifestações contrárias à moralidade pública e aos bons costumes, assim como as especialmente destinadas à proteção da infância e juventude”.

O artigo 127 é mais direto quanto à infância e juventude serem gerações tomadas como "objeto de cuidados e garantias especiais por parte do Estado", que deverá assegurar-lhes "condições físicas e morais de vida sã e de harmonioso desenvolvimento das suas faculdades", ressaltando, ainda, que o não atendimento a este preceito implica em "falta grave dos responsáveis por sua guarda e educação, e cria ao Estado o dever de provê-las do conforto e dos cuidados indispensáveis à preservação física e moral”.

Por fim, o artigo 129 compromete os Poderes Públicos pela oferta de educação à infância e juventude, entretanto destaca que este dever é assegurado aos que "faltarem os recursos necessários à educação em instituições particulares". Ou seja, a obrigação primeira pela educação dos filhos é dos pais e somente será transferida para o Estado, caso a família não consiga arcar com esta despesa. 
Avançando nas reflexões, chegamos a Constituição Federal de 1946, que é bastante poupada no que se refere a garantia dos direitos das crianças, quando trata da obrigatoriedade de assistência à maternidade, à infância e à adolescência em apenas um artigo (art. 164). Representa um retrocesso constitucional, tendo em vista que em momento algum, por exemplo, toma a educação como um direito das crianças.

Passadas duas décadas, em 1967 é promulgada uma nova Constituição ${ }^{4}$ que, tal como a anterior, expressa o direito da infância em apenas um artigo, de número 167, o qual define que "a família é constituída pelo casamento e terá direito à proteção dos Poderes Públicos", instituindo "a assistência à maternidade, à infância e à adolescência" $\left(\$ 4^{\circ}\right)$. Ou seja, além de restringir a concepção de família, em nada amplia as discussões relativas aos direitos das crianças.

Esta breve passagem pelas Constituições Federais brasileiras evidenciou que a legislação nacional, até então, "não concedeu ao menor nem mesmo a honra de ser assunto autônomo a merecer uma seção de um de seus capítulos" (GREGORI,1979, apud NAZARIO, 2014, p. 27). Nos poucos artigos que trataram desta questão, o fizeram "envolta com matéria afim de adultos".

Por fim, atingimos a Constituição Federal de 1988, defendida como a "Constituição Cidadã", e vimos avanços no que diz respeito aos direitos das crianças. Primeiramente, por ser nela que se imprime constitucionalmente o conceito "criança". Ou seja, é a primeira Constituição que trata da ordem geracional (a infância), mas igualmente, demarca a presença do sujeito concreto (a criança).

Vejamos como isso se dá na letra da lei, quando trata do capítulo da Família, da Criança, do Adolescente ${ }^{5}$ e do Idoso (VII), na seção da Assistência Social:

Art. 203 - A assistência social será prestada a quem dela necessitar, independentemente de contribuição à seguridade social, e tem por objetivo:

I - a proteção à família, à maternidade, à infância, à adolescência e à velhice; II- o amparo às crianças e adolescentes carentes. (BRASIL 1988, Grifos nossos).

Muitos outros aspectos poderiam ser analisados no que diz respeito a esta Constituição, entretanto, pela limitação da quantidade de páginas atribuídas para um artigo, passaremos a destacar as questões relativas ao direito das crianças à educação, assegurada desde o nascimento em creches e pré-escolas (Art.208), e reconhecida como um direito social.

“É chamada de Constituição, porém não se constituiu a partir da ação do Poder Constituinte, mas sim de uma emenda constitucional da ditadura. Para além do artigo já citado (art.167), os artigos 158 e 170 tratam do trabalho do "menor" (fixação da idade mínima de 12 anos para ingresso no mercado de trabalho e de 18 anos para trabalho noturno; obrigatoriedade das empresas ministrarem, em cooperação, aprendizagem aos seus trabalhadores menores).

${ }^{5}$ Redação alterada pela Emenda Constitucional n 65, de 2010, que trata da juventude e não mais do adolescente. 
São direitos sociais a educação, a saúde, a alimentação, o trabalho, a moradia, o transporte, o lazer, a segurança, a previdência social, a proteção à maternidade e à infância, a assistência aos desamparados, na forma desta Constituição (BRASIL $1988-$ Art. $\left.6^{\circ}\right)$.

A partir desta legislação percebe-se um esforço constitucional para assegurar o direito à educação dó indivíduo desde a tenra idade, sendo que a criança começa a desfrutar do direito à educação e, paralelamente à proteção, desde o seu nascimento. Ainda segundo a Constituição Federal de 1988, Capítulo III da Educação, da Cultura e do Desporto, seção I da Educação:

A educação, direito de todos e dever do Estado e da família, será promovida e incentivada com a colaboração da sociedade, visando ao pleno desenvolvimento da pessoa, seu preparo para o exercício da cidadania e sua qualificação para o trabalho (BRASIL 1988, Art.205).

Não podemos deixar de registrar, porém, resquícios de velhas concepções sobre os direitos expressos nesta nova Constituição, como o fato de permanecer a ideia de responsabilização da família pela garantia de direitos fundamentais das crianças, anterior a ser assumido como uma obrigação do Estado.

Tomemos o artigo 227 para exemplificar esta situação:

Art.227. É dever da família, da sociedade e do Estado assegurar à criança, ao adolescente e ao jovem, com absoluta prioridade, o direito à vida, à saúde, à alimentação, à educação, ao lazer, à profissionalização, à cultura, à dignidade, ao respeito, à exploração, à liberdade e a convivência familiar e comunitária, além de colocá-las a salvo de toda e qualquer forma de negligência, discriminação, exploração, violência, crueldade e opressão. (BRASIL 1988 - Redação alterada pela EC 65/2010 - Grifos nossos).

Nota-se no artigo acima exposto que não se trata de uma simples inversão de posicionamento das palavras, mas propositalmente atribui-se à família o dever primeiro pela manutenção dos direitos expressos, tal como apontado no artigo 129 da Constituição Federal de 1937, em que competia ao Estado promover educação às crianças e jovens somente na ausência de condições financeiras das famílias.

Resguardada esta ressalva, não podemos negar o salto quanti-qualitativo desta Constituição em relação às anteriores, no que se refere aos direitos das crianças, considerando, ainda, que a mesma abriu precedência para um conjunto de outras legislações promulgadas posterior a1988.

Dentre estas podemos dar ênfase à lei No 8.069, de 13 de julho de 1990, que institui o Estatuto da Criança e do Adolescente (ECA), no qual identificamos no Artigo $4^{\circ}$ que: 
É dever da família, da comunidade, da sociedade em geral e do poder público assegurar, com absoluta prioridade, a efetivação dos direitos referentes à vida, à saúde, à alimentação, à educação, ao esporte, ao lazer, à profissionalização, à cultura, à dignidade, ao respeito, à liberdade e à convivência familiar e comunitária (BRASIL,1990).

Percebe-se que também o ECA reforça a ideia acima apresentada, de obrigação da família anterior ao papel do Estado pela garantia dos direitos das crianças, um posicionamento superado no artigo 54 desta mesma lei, que promulga ser dever do Estado assegurar à criança e ao adolescente: “[...] IV- atendimento em creche e pré-escola às crianças de zero a seis anos de idade" (BRASIL,1990).

Este percurso trilhado pela letra da legislação possibilita identificar que o direito da criança à educação vem ganhando força, vez e voz na esfera pública governamental, tarefa esta, reforçada pela Lei de Diretrizes e Bases da Educação Nacional (LDB 9.394/1996), que oficializa a Educação Infantil como a primeira etapa da Educação Básica (art. 29), considerando este espaço não mais como doméstico, desvinculado do cuidado somente da família, concebendo-a como dever do Estado, embora podendo ser ampliado pelas instituições privadas e organizações não governamentais. "É dever do Estado, garantir a oferta de Educação Infantil pública, gratuita e de qualidade, sem requisito de seleção" (BRASIL,2009, p.1).

Como vimos até aqui, a criança passa a ter o direito oficial à educação, sendo reconhecida, deste modo, como um sujeito de direitos públicos, tanto na esfera social, quanto familiar, levando em conta que a responsabilidade pela educação da criança deixa de ser apenas de competência da família e passa a ser compartilhada, ou seja, o Poder Público e as famílias devem trabalhar juntos para o desenvolvimento integral da criança.

Avançando para a Legislação que rege a Educação Infantil, pretende-se que a criança amplie as habilidades e competências necessárias para o seu desenvolvimento global, em seus aspectos físico, psicológico, intelectual e social (LDB-9394/1996) e, nesta perspectiva, cuidar e educar se constituem em ações indissociáveis.

Nesta perspectiva, se amplia a ideia de currículo da Educação Infantil, que passa a ser concebido como um conjunto de práticas que ao se comprometerem com o desenvolvimento integral das crianças pequenas deve "articular as experiências e os saberes das crianças com os conhecimentos que fazem parte do patrimônio cultural, artístico, ambiental, científico e tecnológico", conforme expresso na Resolução do CNE 5/2009, que trata das Diretrizes Curriculares Nacionais para a Educação Infantil. 
Segue este mesmo documento defendendo que as práticas pedagógicas das instituições de Educação Infantil devem ter como eixo as interações e a brincadeira, de modo a ampliar suas experiências (sensoriais, expressivas, corporais), sua autonomia, propiciar vivências éticas e estéticas com outras crianças e com diferentes grupos culturais; incentivar sua curiosidade e exploração, seu encantamento, o questionamento e a sua indagação, o seu conhecimento em relação ao mundo físico, social e à natureza; possibilitar movimentos amplos, a expressão da sua individualidade e respeito pelos seus ritmos e desejos; proporcionar seu contato com diversas linguagens (musical, das artes plásticas e gráficas, cinema, fotografia, dança, teatro, poesia e literatura); bem como zelar pela proteção da criança, de sua saúde, confiança, respeito, dignidade e convivência. (Art. 9- Resolução $5 / 2009)$.

Ressalta-se, também, a importância que a Educação Infantil tem ao valorizar cada criança como um ser único e com seu modo particular de ver a vida. Deste modo, professores/as e demais profissionais da Educação Infantil têm a responsabilidade de criar condições concretas para que as crianças se apropriem do espírito de respeito e de humildade, estes fundamentais para que haja a valorização e o reconhecimento de cada cultura pelas crianças representadas, segundo o Parecer CNE/CEB20/2009. Ou seja, práticas pedagógicas que alarguem nas crianças suas referências de identidades no diálogo e reconhecimento da diversidade, de modo a contribuir para o seu desenvolvimento integral, criando um espaço democrático, para garantir uma "[...] sociedade livre, justa, solidária e socioambientalmente orientada" (BRASIL,2009a, p.5).

Isto implica que a oferta de uma educação de qualidade e que assegure o exercício da cidadania constitui-se em um meio para minimizar as desigualdades encontradas nas diferentes realidades humanas e, sob este aspecto, o artigo $6^{\circ}$ das DCNEI defendem que este nível educativo deve pautar suas ações em três princípios:

I- ÉTICOS: da autonomia, da responsabilidade, da solidariedade e do respeito ao bem comum, ao meio ambiente e às diferentes culturas, identidades $\mathrm{e}$ singularidades.

II- POLÍTICOS: dos direitos de cidadania, do exercício da criticidade e do respeito à ordem democrática.

III- ESTÉTICOS: da sensibilidade, da criatividade, da ludicidade e da liberdade de expressão nas diferentes manifestações artísticas e culturais (BRASIL,2009).

No que diz respeito à formação exigida para o profissional que atuará diretamente com as crianças nos contextos de Educação Infantil, a LDB (Lei9493/1996) representou um avanço para a área, pois de acordo com Domingues, Saheb, Vaz (2011, p. 3), "ela modificou a visão que se tinha da instituição que oferta a Educação Infantil, estabeleceu critérios para o profissional da área". 
Entretanto, ainda é necessário manter muita atenção sobre este aspecto da formação, se levar com conta que a referida lei deixa margem para dúbia interpretação, como podemos ver a seguir:

Art. 62. A formação de docentes para atuar na educação básica far-se-á em nível superior, em curso de licenciatura, de graduação plena, em universidades e institutos superiores de educação, admitida, como formação mínima para o exercício do magistério na educação infantil e nos 5 (cinco) primeiros anos do ensino fundamental, a oferecida em nível médio na modalidade normal. (BRASIL, 2013 - Redação dada pela Lei no 12.796, de 2013. Grifos nossos).

Se analisarmos os pormenores deste artigo, é possível localizar na letra da lei condições para interpretá-la de acordo com os interesses de quem faz sua leitura, visto que, se a priori ela coloca a exigência de formação em nível superior, imediatamente abaixo ela retira esta exigência, possibilitando que seja em Ensino Médio, na modalidade Normal. Ainda no que diz respeito a quem são os profissionais docentes que atuarão diretamente com as crianças pequenas nos contextos de Educação Infantil, nota-se que não há nenhuma defesa para que seja o pedagogo, mas sim professores habilitados nas mais variadas licenciaturas.

Mesmo com estes impasses, não negamos os ganhos assegurados com esta lei no que diz respeito a definição do profissional, se levarmos em conta a trajetória histórica da Educação Infantil, pela qual já passaram a pajem, a berçarista, a monitora, a auxiliar, entre tantas outras nomenclaturas que compuseram (e ainda compõem) as Redes de Ensino dos municípios brasileiros. Isso reforça que o caráter assistencialista das políticas para o setor, ao se tornar objeto de crítica das pesquisas produzidas, especialmente, a partir da década de 1980, foi cedendo espaço para o caráter educativopedagógico das instituições de Educação Infantil. Tais exigências remetem o profissional que atuava ou atua nas instituições de Educação Infantil a analisar as concepções que amparam a sua prática pedagógica, afim de atualizar-se com as constantes exigências que documentos oficiais e leis agora adotam para a área da pequena infância, de modo a qualificar o trabalho pedagógico realizado com as crianças de 0 até 6 anos de idade. Este percurso implica, necessariamente, na revisão de alguns conceitos que embasam a ação docente, entre eles, os conceitos de criança, infância e educação.

Os Estudos da Infância têm nos apontado algumas direções para que possamos tomar a criança como um ser histórico, social e, em especial, um sujeito de direitos, que na sua vivência com o mundo, constrói sua identidade pessoal e coletiva, formando-se em um ser de e da cultura, que toma para si a cultura adulta, mas que na mesma medida compõe a sua cultura da infância (SARMENTO,2005).

Esta nova forma de conceber as crianças e a infância tem orientado algumas legislações educacionais e documentos oficiais, principalmente, aqueles produzidos a partir da década de 1990, 
como é o caso do conjunto de publicações da Coordenadoria Geral de Educação Infantil do MEC (COEDI), em que se destacam os "Critérios para um Atendimento em Creches que Respeite os Direitos Fundamentais das Crianças" (COEDI MEC,1995/2009). Este documento estabelece doze direitos fundamentais às crianças no que se refere a sua educação em espaço público. São eles:

[...] direito à brincadeira; à atenção individual; a um ambiente aconchegante, seguro e estimulante; ao contato com a natureza; a higiene e à saúde; a uma alimentação sadia; a desenvolver sua curiosidade, imaginação e capacidade de expressão; ao movimento em espaços amplos; à proteção, ao afeto e à amizade; a expressar seus sentimentos; a uma especial atenção durante seu período de adaptação à creche; a desenvolver sua identidade cultural, racial e religiosa (BRASIL, 2009b, p.13).

Percebe-se, com isso, que estamos diante de um conjunto de documentos que aponta "a criança como centro do planejamento curricular", tal como define o parecer CNE/CEB $\mathrm{N}^{\circ}$ 20/2009 (BRASIL, 2009a, p.6) e, neste contexto, ela ganha o adjetivo de capaz, tornando-se protagonista da/na ação pedagógica. Entretanto, não basta somente reconhecer a Educação Infantil como a primeira etapa da Educação Básica e a criança como o centro do planejamento. É necessário, acima de tudo, que

[...] esse direito se traduza realmente em melhores oportunidades educacionais para todos e em apoio significativo às famílias com crianças até seis anos de idade, é preciso que as creches e as pré-escolas, que agora fazem parte integrante dos sistemas educacionais, garantam um atendimento de boa qualidade (BRASIL, 2009b, p.13).

É pelo direito da criança a educação de qualidade que devemos lutar, não por qualquer tipo de educação, mas sim, por uma proposta de Educação Infantil "à brasileira, macunaímica”, como defende Faria (1999, p.71), ao fazer referência a obra "Macunaíma", de Mário de Andrade (1924). Ou seja, uma proposta de Educação Infantil que "garanta o direito à infância e o direito a melhores condições de vida para todas as crianças", sejam elas brasileiras ou estrangeiras; negras, pardas, brancas indígenas ou orientais; pobres ou ricas, entre outros aspectos. E é nesta perspectiva que se insere a defesa pelo direito das crianças ao acesso à linguagem escrita, objeto de análise deste artigo, sobre o qual passamos a dissertar. 


\section{Conceituando alfabetização e letramento na pequena infância: o entrelaçamento das teorias com os pontos de vista das professoras entrevistadas}

Muitos são os discursos que percorrem os conceitos de alfabetização e letramento. Apoiamo-nos na teoria de Magda Soares para aqui trazê-los, de maneira sistemática, relacionandoos, posteriormente, com a sua função na Educação Infantil.

O termo alfabetização tem o carácter da codificação e decodificação de letras, de juntá-las para a construção de palavras. Utilizando-nos das palavras de Magda Soares (2012, p.31): "Alfabetização é a ação de alfabetizar, de tornar 'alfabeto" e ainda ao conceitualizar alfabetização, a autora afirma que "Alfabetizar é tornar o indivíduo capaz de ler e escrever".

Já o termo letramento, no seu primeiro surgimento, ofuscou o conceito que se tinha de alfabetização, ou seja, este termo foi traduzido como alfabetização, como podemos perceber nas palavras de Britto (2005, p. 6): “[...] o conceito letramento foi introduzido no cenário acadêmico e escolar no Brasil. Sabe-se que se trata de uma literatação do termo inglês-literacy-, o qual, durante todo o século passado, traduzido como alfabetização”.

Mais tarde, outros estudos dão outra origem ao conceito de letramento, tendo em vista a necessidade de dar nome ao processo de inserção no mundo da cultura, e não somente a aprendizagem de letras para a construção de palavras, como ainda nos traz Britto(2005, p.9):

Como era forte a tradição de vincular alfabetização à aprendizagem das primeiras letras, parecia haver, segundo alguns autores, a necessidade de buscar outro termo que conceitualmente expressasse a diferença entre esse processo e as formas de inserção no mundo da cultura.

Nesta busca por conceituar letramento, novamente Soares (2012, p. 39 e 40) nos traz a definição de maneira concreta, distinguindo ambos os conceitos aqui levantados, que são diferentes, porém se complementam:

Um indivíduo alfabetizado não é necessariamente um indivíduo letrado; alfabetizado é aquele indivíduo que sabe ler e escrever; já o indivíduo letrado, o indivíduo que vive em estado de letramento, é não só aquele que sabe ler e escrever, mas aquele que usa socialmente a leitura e a escrita, pratica a leitura e a escrita, responde adequadamente às demandas sociais de leitura e de escrita.

Após definirmos estes conceitos, os pensaremos a partir da educação da pequena infância: será possível proporcionar às crianças o contato com a cultura escrita tomando como premissa tais conceitos? Sabemos que ambos são profundamente necessários, de consistência pesada e prioritária no desenvolvimento de uma sociedade justa e autônoma. Sendo assim, a Educação Infantil 
possibilita para a criança o contato com o mundo da escrita e, este sendo letrado, é direito dela participar desta cultura letrada.

Britto (2005, p.16) traz a preocupação de desenvolver o conceito de alfabetização não somente pela sua essência de ensinar as letras, mas, além disto:

O grande desafio da educação infantil está exatamente em, em vez de se preocupar em ensinar as letras, numa perspectiva redutora de alfabetização (ou de letramento), construir as bases para que as crianças possam participar criticamente da cultura escrita, conviver com essa organização do discurso escrito e experimentar de diferentes formas os modos de pensar escrito.

Fazendo uma reflexão, entrelaçando o posicionamento dos autores/as acima apresentados sobre os conceitos de alfabetização e letramento com os dados gerados pela pesquisa de campo, podemos perceber o ponto de vista das professoras sobre tais conceitos a partir das suas práticas pedagógicas na Educação Infantil.

Entretanto, anterior a esta reflexão, importa apresentar como se processou a geração de dados, de forma a ampliar o que foi brevemente anunciado na parte inicial deste texto. Um questionário foi organizado em $2 \mathrm{em}$ blocos, sendo a primeira parte composta por 5 perguntas que contribuíram para a caracterização sobre quem são estas professoras, constando dados sobre suas idades, tempo de atuação na Educação Infantil e sobre os processos de formação inicial e continuada. O segundo bloco continha 5 questões, as quais visavam permitir que as professoras se posicionassem sobre a tarefa da alfabetização e do letramento das crianças na Educação Infantil.

Em reunião com todos os profissionais da instituição foi apresentada a pesquisa, seus objetivos e encaminhamentos, tratado dos critérios para seleção dos sujeitos e levantamento da disponibilidade para participação. A partir da assinatura do termo de consentimento, foi entregue o questionário, solicitado que respondessem e devolvessem no prazo de 15 dias, o qual necessitou ser prorrogado por mais um período de tempo igual.

Em posse dos questionários respondidos, fizemos uma primeira leitura completa e, posteriormente, criamos um quadro em que as respostas foram agrupadas em colunas, de modo que nos permitisse analisar cada uma das questões, comparando-as e registrando aspectos comuns e divergentes entre as respostas.

Deste processo resultou a sistematização dos dados que passamos a abordar desta parte do texto em diante. 
Quando foram solicitadas a conceituar alfabetização e letramento tomando a Educação Infantil como referência, a professora $\mathrm{A}^{6}$ argumentou: "A criança aprende a escrever por meio de seus desenhos utilizando o traçado e a Educação Infantil auxilia com a psicomotricidade fina para evoluir a escrita". A professora B relatou "Alfabetização e letramento na Educação Infantil é vivenciar, proporcionar e ampliar experiências significativas em torno de uma sociedade grafocêntrica". Já a resposta da professora C veio no sentido de demarcar as especificidades de cada um dos conceitos aqui abordados. Para ela: "Alfabetização é reconhecer as letras, saber ler e escrever. Letramento é utilizar a tecnologia da linguagem escrita, em situações práticas do cotidiano, de acordo com a necessidade, habilidade e prazer em ler, saber utilizar a leitura e a escrita como fonte de informação". A professora D afirmou: "Acredito que a alfabetização e o letramento na Educação Infantil andam juntos, pois na Educação Infantil exploramos a escrita de palavras do cotidiano".

Ao nos depararmos com estas respostas identificamos diferentes pontos de vista em torno destes conceitos. No entanto, colocaremos foco sobre a resposta da Professora C, por ter sido aquela que mais se aproximou das reflexões apontadas por teóricos que sustentam este artigo, muito embora ela não tenha feito relação direta com a sua prática pedagógica. Ou seja, vê-se que ela demonstra ter conhecimento teórico sobre os conceitos em questão, porém cabe-nos perguntar: será que ela, no cotidiano institucional, percebe como estes processos se efetivam na prática? Como as crianças se apropriam destes processos? E, em especial, que práticas pedagógicas precisam ser planejadas para assegurar às crianças o acesso significativo ao mundo da escrita?

Dando sequência às análises, ao serem questionadas sobre a importância de trabalhar a alfabetização e o letramento na Educação Infantil, novamente nos deparamos com diferentes pontos de vista. Duas das professoras apresentaram respostas mais restritas, afirmando positivamente a importância, justificando ser "o ponto de partida" (Professora A) ou porque faz "parte do processo de desenvolvimento das crianças" (Professora B). Podemos aferir que elas entendem ser importante que tais processos sejam contemplados na educação das crianças pequenas, mas deixam pistas de que ainda não conseguem argumentar e defender seus pontos de vista.

A professora $C$, ao estender a explicação, trouxe elementos importantes para o debate. Vejamos sua resposta:

\begin{abstract}
Acho importante que desde a Educação Infantil a criança entre em contato com esses conceitos. Afinal, as crianças possuem conbecimentos prévios oferecidos pela sua vida social, não podendo à escola fechar os olhos para isso. Nessa etapa tão importante que é a Educação Infantil, ela não pode ser privada desses conbecimentos que darão base para uma continuidade nos trabalhos futuros.
\end{abstract}

\footnotetext{
6Visando manter o anonimato da instituição e das professoras envolvidas nesta pesquisa, fizemos a opção por denomina-las Professoras A, B, C, D; assim como apresentamos suas respostas se utilizando do recurso itálico, com vistas a diferenciá-las dos teóricos que sustentam este artigo.
} 
Há nesta resposta a demonstração da importância dos processos de alfabetização e letramento para a Educação Infantil, entendendo que a criança está imersa em uma sociedade letrada e, por isso, não é possível desconsiderar seus conhecimentos prévios, os quais deverão ser ampliados no processo educativo institucional. Há, ainda, presente nesta resposta, o entendimento do direito da criança de acesso à cultura escrita.

Por fim, a professora $D$, ao concordar com a importância da alfabetização e do letramento para os processos educativos das crianças, afirma que isso se dá "com tentativas de escrita nas quais as crianças podem aprender com seus erros". Vimos que esta professora tem clareza de que tais processos são marcados pelas tentativas de uma parcela de crianças, com acertos e erros. De que o erro é assumido como suporte para o conhecimento, ao invés de evitá-lo. Mas, sua resposta deixa margem para alguns questionamentos: como a instituição de Educação Infantil tem lidado com o erro? Qual, efetivamente, o lugar do erro no âmbito institucional, em especial, quando das práticas pedagógicas com crianças em idades mais próximas ao ingresso no Ensino Fundamental?

Podemos relacionar as falas destas professoras à defesa de Britto (2005, p. 17), quando este autor afirma que "É a medida que a criança vivencia a experiência dos objetos da cultura escrita, os gêneros de escrita, que ela encontrará sentido no escrito, de modo que, quando aprender o sistema de escrita, ele terá sentido para ela".

Deste modo, entendemos que os professores/as que trabalham com a pequena infância têm o importante papel de proporcionar o contato com os processos de alfabetização e letramento, de maneira que faça sentido para as crianças, que elas percebam a função social da leitura e da escrita, antes mesmo de precisarem codificar e decodificar letras.

Portanto, a Educação Infantil pode se constituir na entrada da criança no universo da escrita formal, mas não se pode desconsiderar que a infância necessita de muitas outras prioridades para se desenvolver integralmente.

Desta forma, este segmento educativo necessita ser acolhedor, instigador, provocador de desejo e promotor do contato ardente com os eixos da Educação Infantil, a saber: as brincadeiras e as interações, ambos os eixos mediados pelas linguagens.

Seguir esta perspectiva implica, necessariamente, entender o desafio posto à Educação Infantil quando o assunto é a participação das crianças na sociedade letrada, tomando Britto (2005, p.20) como referência: 
O desafio da educação infantil não é o de ensinar a desenhar e juntaras letras, e sim o de oferecer condições para que as crianças possam se desenvolver como pessoas plenas e de direito e, dessa maneira, poder participar criticamente da sociedade de cultura escrita.

Após discorrermos sobre o conceito de alfabetização e letramento e apresentarmos o posicionamento das professoras entrevistadas sobre esta questão, vamos agora voltar nossos olhares para a inserção da criança no universo letrado.

\section{O processo de inserção da criança no mundo letrado: o que as professoras entrevistas têm a dizer?}

A criança está inserida em um mundo rodeado de letras, símbolos e desenhos, ou seja, em uma sociedade grafocêntrica.

A linguagem escrita está constantemente presente em nossa sociedade e dela fazemos uso para dar conta de grande parte de nossas ações, permitindo-nos participar das práticas sociais de leitura e escrita que permeiam as relações entre os homens nas sociedades letradas. (ABRANTES, 2013).

Neste contexto, se faz cada vez mais presente a inserção da criança, desde bem pequena, no mundo letrado e a Educação Infantil tem ocupado um importante lugar para que isso se concretize, introduzindo as crianças em práticas sociais de leitura e escrita.

Ao atentarmos às respostas das quatro professoras entrevistadas, novamente conseguimos identificar diferentes posicionamentos frente à pergunta feita: Do seu ponto de vista, compete à Educação Infantil a tarefa da alfabetização e do letramento das crianças?

Três das professoras entrevistadas responderam que não é tarefada Educação Infantil a alfabetização das crianças, visto que "as crianças precisam aperfeiçoar outras babilidades antes de aprender a ler e escrever" (Professoras A e D). Compete, sim, a este nível educativo "proporcionar vivências do mundo letrado, pois habitamos em uma sociedade grafocêntrica e não conseguimos fugir disso" (Professora B) e que é mais indicado "ser iniciado na turma de 5 anos por exemplo" (Professora D).

Neste conjunto de respostas percebe-se um descolamento entre os processos de alfabetização e letramento, como se ambos não se complementassem. Fica evidente a impressão de que para estas professoras a criança não está imersa em um universo letrado e que desperta 
curiosidade, de modo a levá-las a perceber que os símbolos gráficos significam algo, pois observam os adultos se comunicando e obtendo informações a partir deles.

São falas que confrontam a defesa manifestada por Monteiro (2011, p, 13) de que "nenhum adulto tem o poder de deter o conhecimento das crianças". Segue afirmando que "alguns educadores têm o receio de ensinar práticas de alfabetização e letramento por julgarem não ser a hora certa, porém nada pode garantir que o sujeito não aprenda por si próprio".

Talvez estas professoras ainda não conseguem perceber no cotidiano institucional é que as crianças, de posse de um lápis, uma caneta, um giz, um carvão ou um graveto, começam a ensaiar a escrita de símbolos no papel, na parede ou no chão, e que nesta ação estão presentes os processos de alfabetização e letramento, concomitantemente, em uma direção que se aproximada resposta da professora C, quando argumentou que

[...]na educação infantil as crianças precisam estar inseridas em um ambiente encantador, lúdico e estimulante. Esta etapa é um momento rico de aprendiragens, onde aprender é um praz̧er. Acredito que as atividades programadas na educação infantil devem contribuir para o processo destes conceitos (alfabetização e letramento).

Ela demonstra compreender que a Educação Infantil pode, sim, contribuir com as práticas de alfabetização e letramento no cotidiano infantil, por meio de diferentes vivências significadas pelas crianças como experiências que certamente contribuirão para a aquisição da leitura e da escrita convencional, entendendo que "antes mesmo de aprenderem a ler e a escrever [as crianças] realizam descobertas sobre a língua escrita, vivenciando situações reais de seu uso por estarem vivendo em uma cultura letrada"(ABRANTES,2013)

Avançando nas reflexões, foi solicitado às professoras responderem como são trabalhados a Alfabetização e Letramento na Educação Infantil e, para refletir sobre esta pergunta trouxemos para este artigo as falas de duas delas, das Professoras B e C.

Não concordo que a alfabetização e o letramento sejam competência específica da Educação Infantil, mas acredito que ela pode ser trabalhada com vivências diárias, jogos, brincadeiras e diferentes gêneros textuais. (Professora B)

São muitas as práticas de alfabetização e letramento que os professores de Educação infantil podem inserirem seu trabalho. Elas podem ser realizadas durante vários momentos da rotina, tudo dependerá muito do conbecimento e da criatividade do professor (roda da conversa, hora da bistória, da música, das parlendas, manuseio de materiais impressos, etc). (Professora C). 
Pelos indicativos destas é possível pensar que na Educação Infantil o contato das crianças com a cultura grafocêntrica se dá em diferentes momentos da rotina institucional e de diferentes maneiras, sendo que $\mathrm{o} / \mathrm{a}$ professor/a tem papel preponderante no planejamento e na organização dos espaços para que isso se concretize "[...] com vivências diárias, jogos, brincadeiras e diferentes gêneros textuais". (Professora B)

Vejamos exemplos que contribuem para a compreensão do que afirmamos. Quando as professoras mencionam que os processos de alfabetização e letramento se dão a partir de "vivências diárias, jogos, brincadeiras e diferentes gêneros textuais" (professora B), "durante vários momentos da rotina" (professora C), podemos inferir que, na condição de professoras que atuam na Educação Infantil 7 , é recorrente observarmos nos parques dos contextos educativos crianças com gravetos ou partes de brinquedo rabiscando na areia. Ou ainda, em salas de convívio coletivo, se imaginando em um consultório médico ou salão de cabeleireira, fazendo anotações em agendas descartadas pelos adultos, supostamente atendendo a uma ligação telefônica. Ou, então, acessando ao cardápio cria do pela instituição, de modo a escolher o prato do dia. Enfim, estes são alguns dos muitos exemplos do quanto as situações em que a leitura e a escrita se materializam no cotidiano educativo como instrumentos de interações sociais planejadas ou não pelos/as professores/as.

Avançando nas análises, uma das perguntas do questionário tratava da função da Educação Infantil e seus objetivos primordiais, considerando as diferentes faixas etárias em que as professoras atuam.

Vimos que a faixa etária, de certo modo, define os objetos das práticas pedagógicas, visto que para as crianças menores ( 2 e 3 anos), os objetivos apontados pelas professoras se aproximam mais às dimensões do cuidado, como "usar o banheiro (retirada da fralda" (Professora A); da autonomia e construção de sua identidade (Professora B); bem como, do convívio com outras crianças, falando e se comunicando pela oralidade; além de "ouvir e seguir comandos, atenção com suas produçoes" (Professora A).

A Professora C amplia o debate, ao afirmar que:

São vários os objetivos que acho importantes e que contribuem para o desenvolvimento integral da criança: a garantia à criança do conbecimento e aprendizagem de diferentes linguagens; a convivência e a interação com outras crianças, o contato com diferentes materiais, a exploração dos vários espaços, a brincadeira... Porém, na minha opinião para atingir todos os objetivos e para se tornar efetiva a aprendizagem da criança é preciso que a prática pedagógica tenha como foco o encantamento. O professor que incentiva a curiosidade, a exploração, o questionamento.... consegue promover/ampliar os conbecimentos necessários que a criança precisa ter de si e do mundo que à cerca.

${ }^{7}$ No nosso caso, uma como professora de crianças pequenas e, a outra, na formação inicial ou continuada de professores/as que atuam na Educação Infantil. 
Pela resposta, vimos que esta demonstra, mais uma vez, sua real compreensão sobre qual seja o papel da Educação Infantil e, em especial, define o lugar dos/as professores/as nesta proposta. Ela não trata especificamente da alfabetização e do letramento, mas entendemos que ela toca nestes conceitos quando defende ser necessário garantir às crianças "o conhecimento e aprendizagem de diferentes linguagens".

Já para a Professora D, é objetivo primeiro da Educação Infantil "Estímulos ao início do processo da alfabetização, dando inicio ao primeiro contato com o mundo das letras". Talvez por trabalhar com a faixa etária de 5 anos, trouxe como o objetivo principal a alfabetização e o mundo das letras. Entretanto, em pergunta anterior, esta mesma professora afirmou que não concorda que a alfabetização e o letramento sejam competência também da Educação Infantil.

No que tange à função da Educação Infantil, as respostas circularam entre a ideia de um lugar estimulante (Professora D) para que as crianças aprendam "de forma lúdica e atrativa, onde ela aprende a viver em sociedade" (Professora A); que deva "proporcionar vivencias significativas para o desenvolvimento e aprendizagem das crianças" (Professora B) ou ainda, como "primeira etapa da educação básica, tem o papel de educar e cuidar" (Professora C).

Segue esta última professora citada argumentando que no exercício de sua função se sente responsável por "tornar o início da vida escolar da criança um momento praz̧eroso, seguro e oferecer condições necessárias para o desenvolvimento integral de cada uma. Tudo isso de maneira lúdica".

Ao analisarmos essas falas, podemos perceber que as entrevistadas trazem a preocupação de proporcionar aprendizagens significativas, envolvendo atividades lúdicas e prazerosas, rodeadas de estímulos, dando a entender que os direitos sociais precisam ser assegurados às crianças, desde o seu nascimento e que, por isso, "no trabalho pedagógico precisa levar em conta a singularidade das ações infantis e o direito à brincadeira, à produção cultural [...]". (BRASIL, 2007, p.20).

Se faz necessário lembrar, ainda, que muitos professores/as tem dificuldade de compreender como se processa esta prática no cotidiano da Educação Infantil, e quando o assunto é alfabetização e letramento, isto se torna mais remoto, afirmando não encontrar maneiras de trabalhá-los na Educação Infantil.

Contudo, não podemos nos esquecer nunca de que a criança tem direito de acessar o universo da escrita, mas não como forma de preparação para outras etapas posteriores do seu processo educativo, mas sim, de vivências significativas que tomam as brincadeiras, o lúdico e as interações como eixo. Devemos considerar que "as crianças gostam de aprender" e, por isso, nosso objetivo enquanto professores/as de Educação Infantil é "atuar com liberdade para assegurar a apropriação e a construção do conhecimento por todos. (BRASIL, 2007, p. 20). 


\section{Arremate final: algumas considerações}

Ler e escrever é muito mais que juntar letras e formar palavras. Ler é ver mais do que está escrito, é descobrir o que o outro pensou. Escrever époder deixar a nossa marca numa folha, num caderno, no mundo. Ler e escrever é saber que isso foi construido aos poucos, com a ajuda de muitos e a própria força de vontade. (GONTIJO, 2001, p.49).

No limite da quantidade de páginas desta produção, trouxemos algumas considerações para arrematar sobre o que conseguimos apre(e)nder das/com as falas das quatro professoras que atuam na Educação Infantil da rede privada de Blumenau, aproveitando, também, para agradecê-las por suas prestimosas colaborações.

Ao encerrar, queremos deixar registrado que nosso interesse não foi, em momento algum, aferir um julgamento sobre as respostas destas professoras, no sentido de as colocar frente ao binarismo certo - errado.

O teor das respostas apresentadas por estas quatro professoras entrevistadas evidencia, de um modo ou de outro, que algumas delas já superaram a visão restrita de que ler e escrever é mais que juntar letras e formas palavras. Que estas ações implicam em descobrir o que o outro pensou. E que, por isso, devem ser construidas aos poucos e com a ajuda de muitos, tal como anunciado na epigrafe.

Deste modo, convocamos aos professores/as da Educação Infantil que se coloquem como parceiros das crianças nos seus processos de acesso ao universo da escrita, de maneira que cada criança possa apropriar-se socialmente da escrita, através de seus usos sociais, e não, simplesmente, no sentido do domínio do código ou do domínio da tecnologia da escrita, como aponta Soares(2012). 


\section{Referências}

ABRANTES. Natasha Pitanguy de. A vivacidade dos gêneros e seus suportes no Cotidiano da educação infantil: os diversos Contextos e o trânsito real e simulado nas Brincadeiras de faz de conta. In: Congresso Brasileiro de Alfabetização, 2013, Belo Horizonte. Anais do I Congresso Brasileiro de Alfabetização e II Seminário Internacional sobre História do Ensino de Leitura e Escrita,2013.

ANDRADE, Mário. Macunaíma. São Paulo: Arca Literário, 1924.

BRASIL. Constituição Federal de 1988. Brasília: MEC/CNE/CEB, 1988. Disponível em: http://www.planalto.gov.br/ccivil_03/constituicao/constitui\%C3\%A7ao.htm. Acessado em: fevereiro de 2016.

BRASIL. Emenda Constitucional 65, de 13 de julho de 2010. Altera a denominação do Capítulo VII do Título VIII da Constituição Federal e modifica o seu art. 227, para cuidar dos interesses da juventude. Disponível http://www.planalto.gov.br/ccivil 03/constituicao/emendas/emc/emc65.htm Acessado em fevereiro de2016.

BRASIL.Ministério da Educação e do desporto. Conselho Nacional de educação.Câmarade educação básica: Estatuto da Criança e do Adolescente/1990. Brasília: MEC/CNE/CEB, 2009. Disponível em: http://portal.mec.gov.br/index.php?option=com_docman\&task. Acessado em: fevereiro de 2015.

BRASIL.Ministério da Educação e do desporto. Conselho Nacional de educação. Câmara de educação básica: Resolução N5, de 17 de dezembro de 2009. Brasília: MEC/CNE/CEB, 2009. Disponível em: http://portal.mec.gov.br/index.php?option=com_docman\&task. Acessado em: fevereiro de 2015.

BRASIL. Ministério da Educação e do Desporto. Conselho Nacional de Educação. Parecer CNE/CEB No20/2009a. Brasília: MEC/CNE/CEB, 11/11/2009. Disponível em: http://portal.mec.gov.br/index.php?option=com_docman\&task. Acessado em: fevereiro de 2015.

BRASIL. Ministério da Educação. Coordenadoria Geral da Educação Infantil (COEDI). Critérios para o atendimento em creches que respeite os direitos fundamentais das crianças. Brasília: MEC, [1995], 2009c.

BRASIL. Indicadores da Qualidade na Educação Infantil / Ministério da Educação/Secretaria da Educação Básica - Brasília: MEC/SEB, 2009d. Disponível em: http://portal.mec.gov.br/dmdocuments/indic_qualit_educ_infantil.pdf. Acessado em: fevereiro de 2015.

BRASIL. Lei de Diretrizes e Bases da Educação / Ministério da Educação/Secretaria da Educação Básica - $\quad$ Brasília: MEC/SEB, 2009d. Disponível em: http://portal.mec.gov.br/dmdocuments/indic_qualit_educ_infantil.pdf. Acessado em: fevereiro de 2015.

BRIT'TO. Luiz Percival Leme. Letramento e alfabetização: implicações para a educação infantil. O mundo da Escrita no universo da pequena infância/Ana Lúcia Goulart de Faria, Suely Amaral Mello (orgs.). Campinas, SP: Autores Associados, 2005.

DOMINGUES, Thaiane de Góis; SAHEB, Daniele; VAZ, Fabiana Andrea Barbosa. As novas diretrizes curriculares nacionais da Educação Infantil - parecer CNE/CEB nº 20/2009.X Congresso Nacional de Educação - EDUCERE. Curitiba: PUC, PARANÁ,2011. Disponível em: http://www.pucpr.br/eventos/educere/educere2011/.site.Acessadoem:fevereirode2015. 
FARIA, Ana Lucia Goulart de. O Espaço Físico como um dos elementos fundamentais para uma Pedagogia da Infância. In: PALHARES, Marina. Educação Infantil Pós-LDB: rumos e desafios. São Paulo: Autores Associados, 1999.

GONTIJO,C.M.M.O processo de apropriação da linguagem escrita em crianças na fase inicial de alfabetização escola. Tese (Doutorado) - UNICAMP, Faculdade de Educação, Campinas, 2001.

MONTEIRO. Deise Rafaela Scheffel. Alfabetização e letramento na educação infantil: oferendo um espaço de acesso à leitura e escrita antes do ensino fundamental. Porto Alegre, 2010. Disponível em: www.lume.ufrgs.br/bitstream/handle/10183/36525/000818231.pdf. Acessado em: marçode2015.

NAZARIO, Roseli. A infância das crianças pequenas no contexto de acolhimento institucional: narrativas de meninas e meninos na Casa(Lar).Tese (Doutorado) - Universidade Federal de Santa Catarina, Centro de Ciências da Educação, Programa de Pós- Graduação em Educação, Florianópolis, 2014.

SARMENTO, Manuel Jacinto. A Reinvenção do Oficio de Criança e de Aluno. Atos de Pesquisa em Educação - PPGE/ME FURB ISSN 1809-0354 v.6, n.3, p. 581-602, set./dez.2011. Disponível em: http://proxy.furb.br/ojs/index.php/atosdepesquisa/article/view/2821. Acessado em: fevereiro de 2015.

SOARES. Magda. Letramento - Um tema em três gêneros. Autêntica, SP, 2012. VYGOTSKY, Lev S. Formação Social da Mente. São Paulo: Martins Fontes, 1984. 